\title{
Finite Element Analysis of Constrained Total Condylar Knee Prosthesis
}

Project Accomplishments Summary CRADA No. TSB-1152-95

Date: July 13,1998

Revision: 3

A. Parties

The project was a relationship between the Lawrence Livermore National Laboratory (LLNL) and Exactech, Inc.

University of California

Lawrence Livermore National Laboratory

7000 East Avenue, L-795

Livermore, CA 94550

Exactech, Inc.

$\begin{array}{cc}4613 N W 6 \text { th Street; Suite D } 2320 \mathrm{NW} 66^{7 \pi} \mathrm{CT} \\ \text { Gainesville FL 32699- } & 32653\end{array}$

B. Background

Exactech, Inc., is a prosthetic joint manufacturer based in Gainesville, FL. The company set the goal of developing a highly effective prosthetic articulation, based on scientific principles, not trial and error. They developed an evolutionary design for a total knee arthroplasty system that promised improved performance. They performed static load tests in the laboratory with similar previous designs, but dynamic laboratory testing was both difficult to perform and prohibitively expensive for a small business to undertake. Laboratory testing also cannot measure stress levels in the interior of the prosthesis where failures are known to initiate. To fully optimize their designs for knee arthroplasty revisions, they needed range-of-motion stress/strain data at interior as well as exterior locations within the prosthesis.

LLNL developed computer software (especially NIKE3D) specifically designed to perform stress/strain computations (finite element analysis) for complex geometries in large displacement/large deformation conditions. Additionally, LLNL had developed a high fidelity knee model for other analytical purposes. The analysis desired by Exactech could readily be performed using NIKE3D and a modified version of the high fidelity knee that contained the geometry of the condylar knee components. The LLNL high fidelity knee model was a finite element computer model which would not be transferred to Exactech during the course of this CRADA effort. The previously performed laboratory studies by Exactech were beneficial to LLNL in verifying the analytical 


\section{DISCLAIMER}

This report was prepared as an account of work sponsored by an agency of the United States Government. Neither the United States Government nor any agency thereof, nor any of their employees, make any warranty, express or implied, or assumes any legal liability or responsibility for the accuracy, completeness, or usefulness of any information, apparatus, product, or process disclosed, or represents that its use would not infringe privately owned rights. Reference herein to any specific commercial product, process, or service by trade name, trademark, manufacturer, or otherwise does not necessarily constitute or imply its endorsement, recommendation, or favoring by the United States Government or any agency thereof. The views and opinions of authors expressed herein do not necessarily state or reflect those of the United States Government or any agency thereof. 


\section{DISCLAIMER}

Portions of this document may be illegible in electronic image products. Images are produced from the best available original document. 
capabilities of NIKE3D for human anatomical modeling. This, in turn, gave LLNL further entree to perform work-for-others in the prosthetics field.

\section{Description}

There were two purpose to the CRADA:

1. To modify the LLNL High Fidelity Knee Model to accept the geometry of the Exactech Total Knee; and

2. To perform parametric studies of the possible design options in appropriate ranges of motion so that an optimum design could be selected for production.

Because of unanticipated delays in the CRADA funding, the knee design had to be finalized before the analysis could be accomplished. Thus, the scope of work was modified by the industrial partner. It was decided that it would be most beneficial to perform FEA that would closely replicate the lab tests that had been done as the basis of the design.

Exactech was responsible for transmitting the component geometries to Livermore, as well as providing complete data from the quasi-static laboratory loading tests that were performed on various designs.

LLNL was responsible for defining the basic finite element mesh and carrying out the analysis. We performed the initial computer simulation and verified model integrity, using the laboratory data. After performing the parametric studies, the results were reviewed with Exactech. Also, the results were presented at the Orthopaedic Research Society meeting in a poster session.

\section{Expected Economic Impact}

\section{Laboratory Program:}

The computational capabilities in Mechanical Engineering are one of the primary Thrust Areas in the division. Performing this work gave additional experience in hyperelastic materials and composite structures. The project also leveraged funding that was previously awarded for development of the High Fidelity Knee Model.

\section{The Industrial Partner:}

For Exactech, the verification of the improved product resulted in increased sales and increased competitiveness in the marketplace because of improved confidence in the design. They can use the results of the simulation to guide further evolutions of their product.

The U.S. Economy:

The increased competitiveness of the manufacturer resulted in company growth and production. The improved product was more attractive to 
international markets, improving balance of trade. There was also an indirect benefit from the improved health and productivity of the patients receiving these improved prostheses.

E. Benefits to DOE

This project was consistent with the DOE's mission of Technology Transfer and provided benefits and positive impact on both DOE and the partners. This program did not negatively impact any current DOE program.

The NIKE3D capabilities were originally developed to support Defense Programs and will continue in those capacities with respect to new hardware development. A specific potential benefit to DP was developing the capability to model the body as an orthopedic system. For example, concern existed for injury to paratroopers upon impact with the ground. The laboratory's computational capability provided a useful tool for analysis of orthopedic injuries with various protective devices on the body. Also, the capability can be used for any other Defense Program activity investigating loads on the human body.

F. Industry Area Medical prostheses

G. Project Status

The project was completed in July 1996.

H. LLNL Point of Contact for Project Information

LLNL was represented by A. Elaine Ashby (Principal Investigator), L-228, 925/422-9489; 925/424-4991 (fax) of the Mechanical Engineering Directorate.

I. Company Size and Point(s) of Contact

Exactech was represented by Dr. Gary Miller, Vice President for Research and Development; 352/377-1140; 352/378-2617 (fax). Company sales are $<\$ 25$ million, and the company employed 35 people at the time of the CRADA.

\section{J. Project Examples}

There are pictures of the stress levels in the polyethylene tibial component that demonstrate how finite element analysis provided information that was unavailable from contact testing in the laboratory. 
K. Subject Inventions

This small value contractual mechanism did not anticipate any generation of Intellectual Property (IP) including subject inventions. To the best of our knowledge no $\mathbb{P}$ was created.

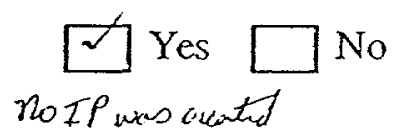

If yes, list all IP created under this agreement

\section{Release of Information}

I certify that all information contained in this report is accurate and releasable to the best of my knowledge.
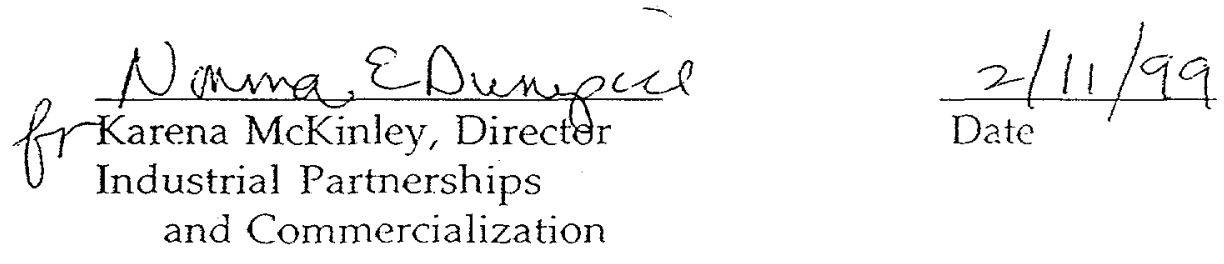

\section{Release of Information}

I have reviewed the attached Project Accomplishment Summary prepared by Lawrence Livermore National Laboratory and agree that the information about our CRADA maype released for external distribution.

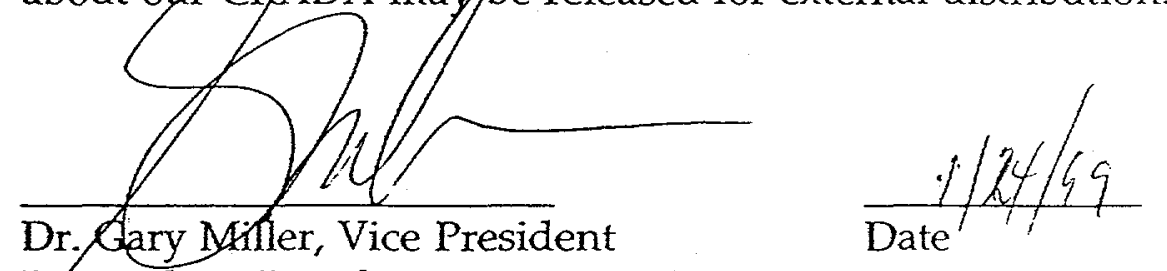

Research \& Development

Exactech, Inc. 